University of Nebraska - Lincoln

DigitalCommons@University of Nebraska - Lincoln

April 1980

\title{
Allocation of Reproductive Effort to the Male and Female Strategies in Wind-Pollinated Plants
}

Cliff A. Lemen

University of Nebraska-Lincoln, clemen2@unl.edu

Follow this and additional works at: https://digitalcommons.unl.edu/natrespapers

Part of the Natural Resources and Conservation Commons

Lemen, Cliff A., "Allocation of Reproductive Effort to the Male and Female Strategies in Wind-Pollinated Plants" (1980). Papers in Natural Resources. 30.

https://digitalcommons.unl.edu/natrespapers/30

This Article is brought to you for free and open access by the Natural Resources, School of at DigitalCommons@University of Nebraska - Lincoln. It has been accepted for inclusion in Papers in Natural Resources by an authorized administrator of DigitalCommons@University of Nebraska - Lincoln. 


\title{
Allocation of Reproductive Effort to the Male and Female Strategies in Wind-Pollinated Plants
}

\author{
Cliff Lemen \\ Field Museum of Natural History, Chicago, Illinois, 60605, USA
}

Summary: Amaranthus and several other wind-pollinated species of plants are used to test some of the theoretical models of relative reproductive effort towards the male and female sexes. Consistent with these models, in self-compatible, monoecious Amaranthus, Chenopodium, Digitaria, Setaria, and Lepidium, female effort represented over $90 \%$ of the total reproductive effort. Also consistent with predictions, Lolium, a self-incompatible wind-pollinated species, was found to have about equal male and female effort. A method is described here that should prove useful in quantifying male and female effort in both wind and insect-pollinated species of plants.

\section{Introduction}

There is a cost associated with any reproductive strategy whether it be parthenogenetic, hermaphroditic, or dioecious, because some energy must be allocated towards the production of offspring. However, much of the recent interest in reproductive strategies has centered on contrasting the ecological and evolutionary tradeoffs among the different reproductive systems.

These costs of reproduction can be categorized into three groups: 1) costs due to loss of reproductive efficiency (number of offspring produced per population member), 2) mating costs (Daly, 1978), and 3) costs related to inbreeding and outbreeding (Williams, 1975). To date much of the investigation of relative reproductive cost has been theoretical, and there is a need for testing present ideas with data. In this context Amaranthus is an interesting genus because it contains both monoecious and dioecious species. Therefore within a group of closely related species it is possible to quantify and compare the relative cost of reproduction for two different strategies. Here I wish to initiate such an effort by reporting the reproductive efficiency and cost of mating in some species of Amaranthus.

Costs due to loss of reproductive efficiency are an inverse function of the average male effort expended by a population. Fisher (1958) proposed that a sexually reproducing and dioecious population should be expending equal effort on each sex; given equal cost for male and female offspring this results in an equal sex ratio. Consequently one half of the population is male and not directly producing offspring. Such dioecious populations must pay this cost as compared to parthenogenetic species (Maynard Smith, 1971a). Hamilton (1967) perceived that if inbreeding is high, the equilibrium sex ratio may no longer be one to one. In the situations he reviewed, more effort was expended on the female strategy by increasing the proportion of female offspring. As the sex ratio swings towards increased production of females, the population as a whole has a greater reproductive efficiency. Maynard Smith (1971 b) has viewed the problem of relative sexual effort in terms of hermaphrodites. He predicted hermaphrodites with external (inefficient) fertilization and self incompatibility will allot equal energy towards each sex. This results in a hermaphroditic population having the same reproductive output as a dioecious population with equal sex ratio. If the hermaphroditic individuals are at least partially selfing, Maynard Smith's model no longer applies. In such cases the logic developed by Hamilton (1967) predicts an allocation of reproductive effort biased towards females as producing a higher reproductive efficiency. As male effort in the population approaches zero, the reproductive efficiency of the population approaches that of a parthenogenetic species.

These models were first developed with animal systems in mind, however plants should conform to these predictions as well, and plants may offer an opportunity for testing these ideas. Within the theoretical framework summarized above, Amaranthus and other wind-pollinated plants can be classified into two groups, outbreeders and inbreeders. The outbreeders satisfy either Fisher's (for dioecious forms) or Maynard Smith's (for monoecious forms) models, and would be expected to invest equal amounts of energy toward each sex. This results in either an equal sex ratio in dioecious species or equal male and female effort in monoecious species. The inbreeders will conform to Hamilton's assumptions and more energy should be channeled into the female sex. As will be discussed below the wind-pollinated species studied here conform to the predictions of these models.

The cost associated with reduction of pollination efficiency is a cost of mating as discussed by Daly, 1978. In Amaranthus there is a considerable tradeoff between the pollination efficiencies of monoecious and dioecious species that has had a large effect on the recent ecologies of these species.

\section{Materials and Methods}

Amaranthus is a wind-pollinated annual herb, with unisexual flowers. Most of the species are monoecious and highly inbreeding. Ten dioecious species exist, and all are from North America. The genus probably originated in the New World tropics but with the aid of man it has become cosmopolitan. The original habitats occupied by Amaranthus were disturbed areas, often along water courses or bodies of water. Many of the species have now spread to man-made disturbed areas such as cultivated fields and road- 
Table 1. Seed weights and anther volumes for several species are shown. The anther volumes were found by measuring the anthers' lengths and widths.

\begin{tabular}{lllll}
\hline Species & $\begin{array}{l}\text { Seed Wt. } \\
(\mathrm{mg})\end{array}$ & $\begin{array}{l}\text { Seeds/ } \\
\text { Flower }\end{array}$ & $\begin{array}{l}\text { Anther Vol. } \\
\left(\mathrm{mm}^{3}\right)\end{array}$ & $\begin{array}{l}\text { Anthers/ } \\
\text { Flowers }\end{array}$ \\
\hline A. powellii & 0.60 & 1 & 0.062 & 3 \\
A. hybridus & 0.39 & 1 & 0.054 & 5 \\
A. palmerii & 0.53 & 1 & 0.166 & 5 \\
A. tamariscina & 0.21 & 1 & 0.157 & 5 \\
L. perenne & 2.08 & 1 & 1.28 & 3 \\
C. album & 0.88 & 1 & 0.025 & 5 \\
D. sanguinalis & 0.63 & 1 & 0.013 & 3 \\
S. geniculata & 0.37 & 2 & 0.025 & 2 \\
L. virginicum & 0.875 & 1 & 0.029 & 3 \\
\hline
\end{tabular}

sides. Amaranthus has also been used by man, either being cultivated for its seeds or used as a green. Its use as a forage plant by livestock has earned it its common name, pigweed.

To compare reproductive strategies in pigweed several species were used, 2 monoecious: A. powellii (S. Wats.) and A. hybridus (L.), and 3 dioecious: A. palmeri (S. Wats.), A. tamariscina (Nutt.) and $A$. altissima (Riddell). All specimens were collected in northern Illinois except for A. palmerii, which came from El Paso, Texas.

Other species used here are Lolium perenne (L.), Digitaria sagnuinalis (L.), Setaria geniculata (Lam.), Lepidium virginicum (L.). The first species, L. perenne, is wind-pollinated and self-incompatible, the rest are wind-pollinated self-compatible.

Seed weights were found for all the species under study. Anther volumes were also determined by a measuring method. Results of both quantifications are shown in Table 1 .

In contrast to the other monoecious species used here the monoecious Amaranthus has unisexual flowers. It was therefore necessary to ascertain the ratio of male to female flowers on these plants. The male/female flower ratios were: powellii 43/524 or $7.6 \%$ and hybridus $26 / 241$ or $9.7 \%$.

The sex ratios in two dioecious species were observed. In the areas studied the sex ratios (proportion of males in the population) were: A. palmerii 0.55, (22/40); A. altissima 0.37 (42/114). The sex ratio of $A$. altissima is statistically different from $1: 1$ in this sample. However, this may be due to differential survival or habitat preferences. Evidence from Murray, 1940, indicates an equal production of male and female seeds in dioecious species of Amaranthus. A consistent pattern in the dioecious species was for the males to be smaller than the females. This pattern can be documented with A. palmerii, where it was found that males weighed significantly less than females (Mann-Whitney U test $\mathrm{p}<0.001$ ). Smaller males appear to be the normal case in dioecious annuals (Lloyd and Webb, 1977).

Finding the relationship between the size of an individual Amaranthus plant and the number of flowers it produced was requisite to the calculation of male and female effort in the dioecious forms. Therefore both male and female plants were harvested in late fall at the end of their reproductive cycle, when flowering had stopped or greatly slowed.

The number of flowers on a plant was too large to be counted directly so an estimation method was used. This estimation method required two things. First, the number of flowers on inflorescences of differing lengths were counted for four species. These relationships were quantified with regression analyses that are
Table 2. Results from the regressions of the number of female flowers on an inflorescence (dependent variable) and the length of the inflorescence, both variables were log transformed, and all the regressions were significant at the 0.01 level.

\begin{tabular}{|c|c|c|c|}
\hline & b & a & $\mathbf{r}$ \\
\hline A. powellii & 1.69 & 0.15 & 0.99 \\
\hline A. hybridus & 0.67 & 0.98 & $0.99^{\mathrm{a}}$ \\
\hline A. palmerii ㅇ & 0.79 & 3.2 & 0.98 \\
\hline A. tamariscina 우 & 0.97 & 3.1 & 0.99 \\
\hline A. palmerii ठ̋ & 0.72 & 3.3 & 0.99 \\
\hline A. tamariscina & 0.84 & 3.3 & 0.95 \\
\hline
\end{tabular}

Table 3. The number of flowers scored and the percent found to be fertile are shown for three species of Amaranthus.

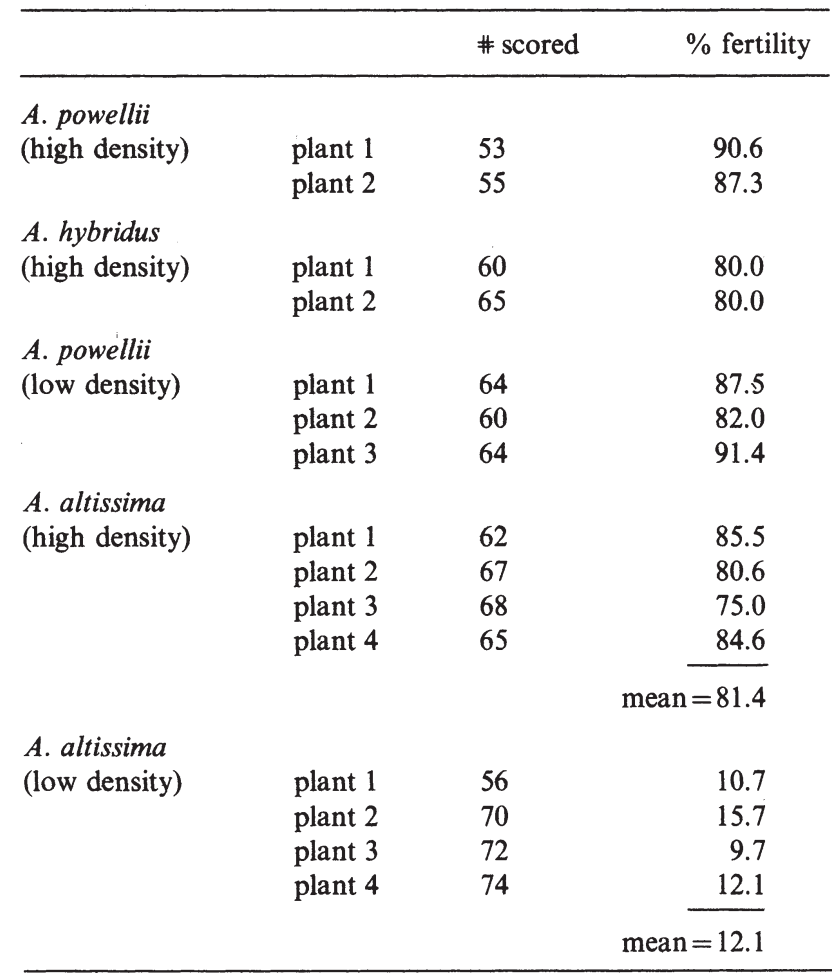

shown in Table 2. Second, all the inflorescences on these plants were measured. By using the regression equations of Table 2 and the inflorescence lengths, estimates of the total number of flowers on a plant could be made. For each of the plants used in this analysis, dry weights of the plant above ground were also obtained.

Percent fertilization was found for three species: the monoecious A. hybridus and A. powellii, and the dioecious A. altissima. In areas of intraspecific high density (conspecifics within one meter) powel$l i$ and hybridus averaged $86 \%$ fertility (Table 3 ). This fertility estimate is undoubtedly a minimum estimation of the rate of pollination because other factors besides the lack of pollination could cause the lack of development in a female flower. Three individuals of $A$. powellii were found growing in low density areas (more than $15 \mathrm{~m}$ to nearest conspecific, and in one case more than $100 \mathrm{~m}$ ) and their percent fertility also measured, Table 3 . The fertility of $A$. altissima was observed at two sites along a sand bar on the Kankakee River, Illi- 
nois. At one site altissima was at high density, at the other low density. In the high density site all females sampled had at least one male plant within a meter. In the low density site the average distance to the nearest male was six meters. These two areas were separated by about $15 \mathrm{~m}$. The results are shown in Table 3 .

\section{Discussion}

This paper deals in relative efforts, so it is not vital to quantify the absolute allocation of effort made to each sex. Further simplifying the analysis, all plants studied here have extremely small simple flowers. For this reason I will consider the production of anthers and seeds as the only important cost of flowering. The anther size was determined by direct measurement to find volume, and the seeds were weighed. Certainly other indices exist for quantifying pollen and seed production. However, even if anther weight, or calorie content of the pollen and seeds are used, a correction factor will be needed to equate the male and female indices of effort. Ten grams of pollen may not cost the plant the same as ten grams of seed. Cost must be considered not in absolute weight or calorie content, but in the ability of the plant to produce these substances. Clearly then the critical issue is to quantify a conversion factor, $\mathrm{C}$, for the indices of sexual effort chosen. The dioecious species give the information necessary for this conversion. In semelparous species the reproductive effort can be assumed maximal at the only reproductive event. Further, it is assumed in the annual pigweed, male and female plants of the same size have equal reproductive effort to invest. Therefore, I can equate the reproductive output of the two sexes. The following relationship can be defined :

C - Total anther volume on plant $=$ Relative male effort

(1) Total seed weight on plant

where $\mathrm{C}$ is a correction factor to relate energetic cost in seed weight to cost in anther volume. Equation (1) should be used only when comparing male and female parts on one plant or when comparing male and female parts on plants of equal size in dioecious species. In the case of the dioecious Amaranthus this was done by using the average plant weight for each species and calculating the expected number of female and male flowers for a plant of that size using regression equations of Table 2 . By assuming maximal and equal effort by both sexes in dioecious species the ratio of male to female effort is 1.0. Using this relationship, $\mathrm{C}$ can be calculated as $0.7119(95 \%$ confidence limits of mean are from 0.6064 to 0.8333 ) for $A$. palmeri, and 0.6446 (confidence limits are from 0.2463 to 0.9385 ) for $A$. tamariscina. The confidence limits are much smaller for A. palmeri; however, the mean estimate for tamariscina is within the confidence limits of $A$. palmeri. As there is no statistical difference in the means, they are averaged. Using an average value for $\mathrm{C}$ of 0.6783 the relative male to female effort can be calculated for the monoecious species. The allocation of energy towards the female strategy in the monoecious species of Amaranthus is $98.4 \%$ and $95.6 \%$ of the plants total reproductive effort. These results are consistent with the high rate of inbreeding found in these species (Hamilton 1967, Sauer 1957). Figure 1 shows the relative male effort for all the Amaranthus species using the average value of $\mathrm{C}$.

As only $1.6 \%$ and $4.4 \%$ effort are being directed in male reproductive effort in these two monoecious species, seed crops should be nearly identical to female individuals of the dioecious

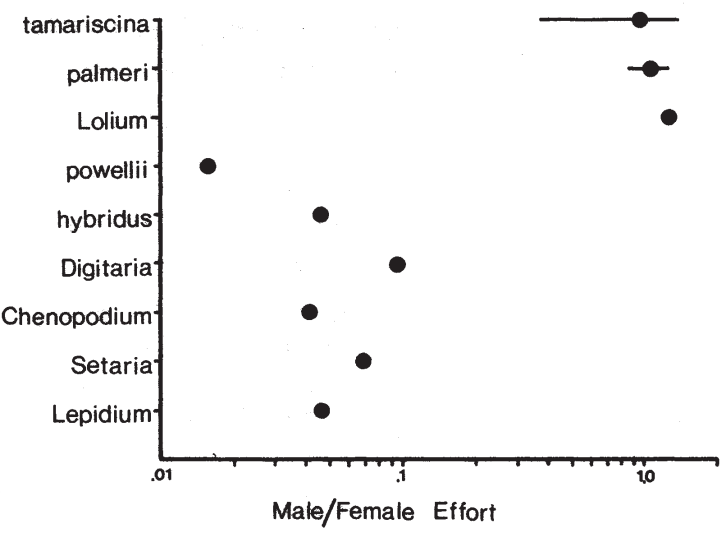

Fig. 1. Graphical representation of the relative male effort for the nine species used in this study (for the complete species names see text). The top three species Amaranthus tamariscina, A. palmeri (shown with $\pm 2 \mathrm{SD}$ ), and Lolium perenne are self-incompatible, all other species represented here are self-compatible.

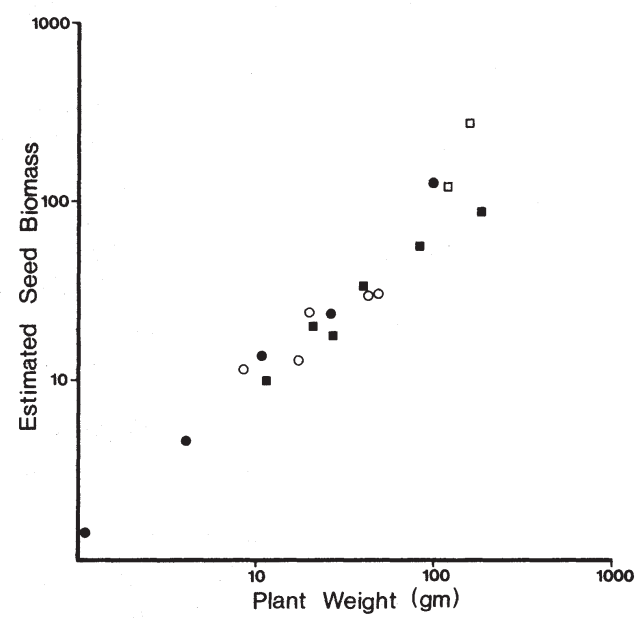

Fig. 2. Scattergram of the projected seed biomass (grams) and plant weight. The species shown are $A$. palmerii, closed circles; A. tamariscina, closed squares; $A$. powellii, open circles; and $A$. hybridus, open squares.

species. Once again using the regression equations in Table 2 it is possible to compare the seed output of monoecious and dioecious species of Amaranthus. Because of differences in seed size among species direct comparisons are not possible. To adjust seed production so that comparisons can be made, biomass estimates of potential seed crops were made using average mature seed weights. This seed biomass estimate is a hypothetical projection as many of the female flowers were far from having mature seeds. The results of this transformation are shown in Fig. 2. There is no statistical difference in seed biomass production between the dioecious females and the monoecious hermaphrodites. Because all individuals produce seeds the hermaphroditic populations are nearly twice as productive as dioecious populations. This is the predicted result because of the high rate of inbreeding in monoecious Amaranthus.

How conservative is $\mathrm{C}$; how distant a taxonomic group could be used in equation 1 and still obtain meaningful results? I cannot rigorously answer that question here, but I have inserted some other wind-pollinated plants into the equation. The results are shown in Fig. 1. Chenopodium, Digitaria, Setaria, and Lepidium are all 
inbreeders, and as predicted they show low male effort. Lolium perenne is monoecious with perfect flowers but is self-incompatible and so conforms to Maynard Smith's model. As predicted, the ratio of male to female effort in Lolium is near one, Fig. 1. All these results are in line with predictions even though Lolium and Digitaria are distantly related to Amaranthus (monocot vs. dicot).

In the self-incompatible group of three species no statistical difference exist among the relative male effort estimates (t-test, $\mathrm{p}>0.05)$. In the self-compatible group of six species no statistical inference can be made on possible differences among species because there are no estimates of within species variances. However, this is not the important issue, the model only predicts there should be much less male effort in these species as compared to the self-incompatible species. Consistent with this prediction the difference between the greatest relative male effort for a self-compatible species (0.096) and the least male effort for a self-incompatible species $(0.950)$ is almost one order of magnitude. The mean relative male effort for the self-compatible group is 0.06 and the mean male effort for the self-incompatible group is 1.09 . These two groups have a statistically significant difference in male effort (by a t-test: $\mathrm{DF}=7, \mathrm{t}=17.02, \mathrm{p}<0.0005$; or by a Mann Whitney $\mathrm{U}$ test: $\mathrm{N}_{1}=3, \mathrm{~N}_{2}=6, \mathrm{U}=18, \mathrm{p}<0.025$ ).

Another cost associated with outcrossing is the decreased probability of fertilization. This cost has received little attention by theoreticians but in wind-pollinated species such as Amaranthus its effects are dramatic. In high density situations percent fertilization is approximately equal in monoecious and dioecious species (Table 3 ). When interplant distance rises to even a modest five or six meters the fertility rate of the dioecious altissima fell by a factor greater than five, from $81 \%$ to $12 \%$. In the monoecious powellii plants with no conspecifics within from 10 to $100 \mathrm{~m}$ had the same fertility rate as monoecious plants in high density areas, Table 3 . These results underscore the advantages of selfing in colonizing species (Baker, 1965). In Amaranthus many of the monoecious species have become world-wide weeds by colonizing man-made disturbances. The success of the dioecious species at colonizing these new habitats has been much less (Sauer, 1957). Repeated examples have been found of a lone individual of a dioecious species growing far out of its normal range, and, naturally, it is incapable of reproducing. However, at a much slower rate, through repeated introductions some dioecious species are widening their range. This is particularly true of A. palmerii and A. tamariscina. At this time some dioecious species have reproducing populations in Europe (Sauer, 1972).

\section{Conclusions}

I have measured two costs of reproduction in Amaranthus and other wind-pollinated species that can be directly attributed to costs of outcrossing. First there is the cost of reproductive efficiency. A wind-pollinated species that is self-incompatible will spend equal effort on each sex whether the species is dioecious (Amaranthus) or monoecious (Lolium). This strategy will result in a reproductive output per individual of about one half of a selfing species.

The second cost of outbreeding, reduction of pollination efficiency, derives from the fact that obligate outcrossing (monoecious or dioecious) will at times be found in low density situations. Evidence from pigweed shows that on the local scale a few meters can cause a sharp decrease in seed set. Over longer dis- tances obligate outbreeders are completely sterile and thus make poor colonizers. Highly inbred species do not have this problem, fertility is unchanged in high and low density.

Given the high cost of outcrossing there must be large benefits also, because outcrossing is extremely common in angiosperms. The conventional wisdom is that in most situations the benefits of crossfertilizations outweigh the cost (de Neltancourt, 1977). Inbreeding is viewed as a specialization to particular ecological situations and represents an evolutionary dead-end (Stebbins, 1957). One such situation where inbreeding is thought to be favored is in weedy or colonizing species (Allard, 1965; Baker, 1965). Here the importance of high fecundity, long range dispersal, and the lack of competitors in disturbed habitats partially offsets the benefits of outcrossing. If inbreeding in Amaranthus is a response to its colonizing way of life, it would be satisfying if there was some basic dicotomy in the ecologies of monoecious and dioecious species. Unfortunately, except for the fact that all dioecious species are North American, there seems little difference between the inbreeders and outbreeders. Most species in the genus grow in recently disturbed habitats, often in sandy soils, along streams, rivers, ponds, lakes or oceans. The only difference seems to be one of colonizing ability. It is interesting that this difference is not due to the amount of outcrossing, but is a function of decreased fertility with distance from potential mates.

Acknowledgments. Special thanks to Patricia W. Freeman and the Field Museum of Natural History for their aid and support during the preparation of this paper.

\section{References}

Allard, R. W.: Genetic systems associated with colonizing ability in predominantly self-pollinated species. In: The Genetics of Colonizing Species. (Baker, H. G. and G. L. Stebbins eds.), New York Academic Press 1965

Baker, H. G.: Characteristics and modes of origin of weeds. In: The Genetics of Colonizing Species. (Baker, H. G. and G. L. Stebbins eds.), New York Academic Press 1965

Daly, M.: The cost of mating. American Naturalist 112, 771-774. (1978)

Fisher, R. A.: The Genetical Theory of Natural Selection. Dover, New York (1958)

Hamilton, W. D.: Extraordinary sex ratios. Science 156, 447-488 (1967)

Lloyd, D. G., Webb, C. J.: Secondary sex characteristics in seed plants. The Botanical Review 43, 117-216 (1977)

Maynard Smith, J.: What use is sex. Journal of Theoretical Biology 30, 319335 (1971a)

Maynard Smith, J.: The origin and maintenance of sex. In: Group Selection. (Williams, G. C. ed.), Aldine Atherton Inc. Chicago 1971b

Murray, M. J.: The genetics of sex determination in the family Amaranthaceae. Genetics 25, 409-431 (1940)

Nettancourt, D. de: Incompatibility in Angiosperms. Springer-Verlag, Berlin (1977)

Sauer, J. D.: Recent migration and evolution of the dioecious amaranths. Evolution 11, 11-31 (1957)

Sauer, J. D.: The dioecious Amaranthus: A new species name and major range extensions. Nadrono 22, 426-434 (1972)

Stebbins, G. L.: Self-fertilization and population variability in higher plants. American Naturalist 91, 337-354 (1957)

Williams, G. C.: Sex and Evolution. Princeton University Press, Princeton (1975) 